\title{
Abnormal Electrophysiological Activation in Schizophrenics during a Personal Traits Attribution Task
}

\author{
JAIME R. SILVA ${ }^{1}$, WALTER M. TORRES ${ }^{1}$ and MANUEL S. ORTIZ ${ }^{2}$. \\ ${ }^{1}$ Departamento de Salud Mental y Psiquiatría, Universidad de La Frontera \\ 2 Departamento de Psicología, Universidad de La Frontera
}

\begin{abstract}
Changes in personal identity have been described as a major component in the expression of schizophrenia. Considering current evidence that relates the cortical structures of the medial line with the self, we hypothesize that there are differences in the frontomedial electrophysiological activation in schizophrenics when compared to normal subjects during tasks that require this function. In an experimental design, 9 schizophrenic and 7 normal subjects participated in a personal traits attribution task regarding the attribution of the self, another person and a simple reading. Electric brain activity was recorded with a dense array of 128 electrodes, with evoked brain potentials being obtained for the three conditions. Considering the evoked potential morphology, repeated measures ANOVA were performed on the adaptive mean for the 180-230 ms time window (P200) in the frontomedial electrodes, with a group effect being found $(\mathrm{F}=5.352 ; \mathrm{p}=0.038)$. Comparisons of the groups show that the schizophrenics presented less voltage in the self condition $(\mathrm{t}=2.386$; $\mathrm{p}=0.033$ ). Although the results are not consistent with the hypothesis, it can be suggested that the early modulation of word-related meaning formation in a self-referential context could be affected in schizophrenia.
\end{abstract}

Key words: schizophrenia, event related potential, self.

\section{INTRODUCTION}

Schizophrenia $(\mathrm{SCH})$ is a chronic mental disorder, probably of multifactor origin, characterized by cognitive, affective and social dysfunctions (DSM IV; Friston et al., 1987). In this disease, there is a great deal of evidence with respect to functional and anatomical abnormalities, particularly in the frontotemporal regions and their connections to other brain structures (Woodruff et al., 1997; Sigmundsson et al,. 2001).

In schizophrenic patients, multiple changes have been reported in cognitive functions, for example memory, language, attention span and visual processing (Goldberg \& Gold, 2000; Orellana et al., 2006). In this context, personal identity and self-reference, as will be described, also represent a relevant dimension in the expression of this disease (Bocker et al., 2006; Torres et al., 2007).

\section{Schizophrenia and personal identity}

Although currently the change in personal identity or self is not present on the list of $\mathrm{SCH}$ diagnostic criteria, it has been implicitly recognized as an essential component of the clinical symptoms, including in the typical nosography, among the positive as well as the negative symptoms (Bocker et al, 2006; Saas, 2003). Effectively, independent research groups have designated disorders of the self as fundamental to the disease (Saas and Parnas, 2003), proposing new taxonomies (Scharfetter, 1981) and attempting to prove empirically their change based on psychometric (Scharfetter, 1995; Robricht and Priebe, 2004) and neuropsychological (Bocker et al., 2006) tests. Within this framework, it has been reported that patients with $\mathrm{SCH}$ have difficulties in processing information related to the self (Gallup et al., 
2002; Kircher \& David, 2003) and in theory of mind attribution tasks (Corcoran et al., 1995; Frith and Corcoran, 1996), hypothesizing that the latter is secondary to the deficit for the capacity to recognize oneself (Gallup, 1988). Daprati et al. (1997), for example, concluded that schizophrenic patients have difficulty distinguishing between their own hand and that of someone else when it is presented on a television screen in real time. Similarly, Kircher and David (2003), in a study with schizophrenic patients, evaluated their ability to recognize their own face, that of a family member and that of a stranger, concluding that in those patients, there was a change in the processing of the self. Finally, studies on subjects with schizotypical personality traits report difficulties in attributing mental states, probably secondary to the change in this same processing (Gallup, 1982; Gallup \& Platek, 2002).

\section{Medial line cortical structures (MLCS) and the self}

The stimuli related to processing the self consistently recruit the MLCS, including the dorsal prefrontal and orbitomedial cortices and the anterior and posterior cingulates. Current reports demonstrate a strong relation between the MLCS and selfreferential stimuli processing in normal subjects (Northoff et al., 2006; Vogeley et al., 2001) under different experimental task (For a detailed review, see Northoff \& Bermphol, 2004). Of interest to this study is the evidence of differential activation of frontomedial brain structures (i.e. anterior cingulated cortex) when the reflection about one's own personality trait is compared to reflection regarding the personality of a well-known public figure (Zysset et al., 2002) or neutral stimuli (Craik et al., 1999). In a recent study, Tucker and Luu (2003) found that the attribution of personal traits (a personality descriptor) produced electric activity in the anterior medial line that does not appear during a simple reading of the same stimulus. It was demonstrated in a source analysis that this condition originated in the anterior and posterior cingulated cortices.
Taken together, neurophysiological research suggests the participation of medial line brain structures, particularly frontomedial, in the processes associated with personal image, both conceptual (Tucker et al., 2003) and physical (Kjaer et al., 2002).

Although $\mathrm{SCH}$ is a disease where the changes in self appear to be highly relevant, it is not known whether there is a neurophysiological or neuroanatomical correlate of this dysfunction. As will be described, the MLCS and their participation in identity processing, probably play an important role in this respect.

Electrophysiological activation in schizophrenic subjects during a selfreferential task

In contrast to reports on schizophrenic patients regarding changes in attention span, memory (Ford, 1999) and associated psychobiological processes (i.e. P300) (Polich, 1995), there is scant evidence and practically no studies that deal with the abnormalities of the self from a psychophysiological point of view. The conclusive evidence about alterations in P300 amplitude (Jeon and Polich, 2003) and their asymmetric topography (Jeon and Polich, 2001) in these patients suggests that self-referential processing of stimuli may also demonstrate disorders in the brain activation pattern. As presented in the research program in which this study took place (Torres et al., 2007), and as is derived from the evidence in the previous section, MLCS and their role in generating personal identity may present an anatomical and/or physiological pathology in $\mathrm{SCH}$. From the point of view of anatomical abnormalities, numerous studies have reported on this disorder, anomalies in the structure of the prefrontal cortex, the anterior cingulated cortex and the temporal cortex (Woodruff et al., 1997; Sigmundsson et al., 2001) among others; however, there is no evidence exploring the existence of changes in the functions of these structures in selfreferential tasks.

In order to partially deal with this hypothesis, this study attempts to ascertain 
the electrophysiological differences between normal subjects and schizophrenic patients in a self-referential task. We hypothesize that there are differences between schizophrenic and normal participants in the event related potentials (ERP) amplitude, mainly in frontomedial electrodes, in a personal traits attribution task. This experimental task has been shown to engage frontomedial structures in previous research (Tucker et al., 2003).

\section{MATERIALS AND METHODS}

\section{Participants}

Once approval had been received from the Scientific Ethics Committee of the Araucanía Sur Health Care Service, the study was explained to each participant, both verbally and in writing, with each signing an informed consent form prior to his or her inclusion. Twelve patients from the Psychiatric Service of the Hospital Dr. Hernán Henríquez in Temuco took part. All the patients were male, right-handed and complied with the criteria of $\mathrm{SCH}$ according to the World Health Organization's International Classification of Diseases (10 $10^{\text {th }}$ revision). The diagnosis was made by a psychiatrist in the Department of Mental Health and Psychiatry from the Universidad de La Frontera. Those with an additional diagnosis of organic brain disorders, mental retardation, drug dependency or who had received electroshock therapy in the last year were not included in the study. All were receiving antipsychotic medication at the time of the experiment. After the procedure, 4 patients were excluded due to a lack of analyzable information because of excessive eye movement or an insufficient number of answers offered in the time required for the experiment. The control group was made up of 10 subjects with no personal or family history of $\mathrm{SCH}$ or neurological disorder. After the procedure, 3 subjects were excluded for the same reasons as the experiment group. In both groups, an initial interview was conducted in which general and clinical data were obtained; in the patient group, the interviews were complemented by a review of their clinical records. Each participant was compensated with the equivalent of US\$10 in national currency. The characteristics of the schizophrenic and control subjects ultimately included in the study are shown in Table 1.

\section{Instruments}

Electroencephalograph: A 128-channel digital electroencephalograph (Geodesics, Eugene, OR) was used with an electrode net that ensures subject comfort and fast application. E-Prime 1.0 software and a $100-\mathrm{MHz}$ Pentium PC were used for stimulus presentation and the response register.

TABLE I

Sample characteristics. The values in parentheses correspond to standard deviation

\begin{tabular}{lcc}
\hline & Experiment Group & Control Group \\
\hline Age & $30.7(9.4)$ & $28.4(4.6)$ \\
Education (years) & $12.3(1.6)$ & $15.4(0.53)$ \\
Subtype & Paranoid & No psychiatric diagnosis \\
Time lapse since diagnosis (years) & $10.4(9.4)$ & No psychiatric diagnosis \\
Treatment & Clozapine & No pharmacological treatment \\
$\mathrm{N}$ & 8 & 7 \\
\hline
\end{tabular}




\section{Procedure}

Once consent had been obtained and having complied with inclusion criteria, the subjects underwent an experimental task of self (self-referential) / someone known (heteroreferential) personality traits attribution.

The list of descriptor words of traits used was that designed by Tucker et al. (2003) and translated into Spanish. In all, 160 words were used: 80 represented a positive trait and the rest a negative trait. The words were presented in 4 blocks of 40 words each for each condition. There were two attribution conditions, one called "self", where the subject had to decide for each attribute presented whether this trait was applicable or not to his "personality". In a second condition called "other", the subject had to answer whether an attribute was applicable or not to a previously defined friend/acquaintance. In a third condition, the subject had to read the word. The order of the conditions was counterbalanced across the subjects. Each trial began with a $2000 \mathrm{~ms}$. fixation point $(+)$ on the screen, then each word was presented for $500 \mathrm{~ms}$ and finally $1000 \mathrm{~ms}$. were left for subject response. Each subject performed 10 blocks of trial practice.

\section{EEG recording and ERP derivation}

During the experimental procedure, a continuous EEG was obtained with impedance kept below $50 \mathrm{~K} \Omega$, using a sample of $250 \mathrm{~Hz}$ and a pass band filter of 0.1 - $100 \mathrm{~Hz}$. The ERP were obtained offline by averaging all the assays of a given condition. The segmentation was performed for each trial considering the stimulus presentation, $100 \mathrm{~ms}$ before and $1000 \mathrm{~ms}$. after. Subsequently, EEG grand averages were obtained to emphasize the EEG patterns shared by all the subjects of a group or condition. To achieve this, we began by filtering the continuous EEG record with a pass band of $1-9 \mathrm{~Hz}$. Then, the filtered register was segmented into categories according to experimental conditions of interest ("Oneself", "Other", "Reading"). To automatically detect the artifact contained in the segments obtained, the artifact detection algorithm of the Netstation 4.0 program was used. The following criteria were adhered to for detecting erroneous segments: Maximum Number of Bad Channels (Maximum 10 bad channels); Blink Threshold $(70 \mu \mathrm{V})$ and Eye Movement Threshold $(70 \mu \mathrm{V})$. Then, an eye inspection was performed over the results and those segments with artifact were eliminated. Once the corresponding segments were obtained and taking into account the high number of available channels (128), those channels with incorrect registrations were replaced. The non-rejected segments were immediately averaged for each category created during the segmentation (self, other and reading). The data obtained were referred to the average and corrected for the polar average reference effect (Junghoefer et al., 1999). Then, the ERP grand averages were obtained among the categories for the subject groups, with a baseline correction finally being performed, subtracting the record average of $100 \mathrm{~ms}$ prior to beginning stimulus.

\section{Data Analysis}

The ERP grand averages were inspected visually for each condition and group in the electrodes of interest, as well as the resulting topographical maps, with these latter being processed in animations of the progression of voltage variations in the electroencephalographic register. In addition, based on the amplitude variations observed in the grand averages, the statistical differences of the adaptive media of the brain voltage variations were analyzed in the time windows: $180-230 \mathrm{~ms}$, 310-380 $\mathrm{ms}$ and 415-490 for frontomedial electrodes (6, 13, 113, 7 and 107), Fp1, Fp2 and $\mathrm{Cz}$; and 75-175 ms for electrodes P3, $\mathrm{P} 4, \mathrm{O} 1$ and $\mathrm{O} 2$.

\section{RESULTS}

Multiple analyses were performed on the average variations (adaptive mean) of the brain voltage in the montage of the 
electrodes selected and in the time windows of interest. Due to space limitations, only the most relevant results are reported. A repeated measures ANOVA with a between-subjects factor ( $\mathrm{SCH}$ and normal) and a within-subject factor (self and other) was performed on the adaptive means for the 180-230 $\mathrm{ms}$ time window in the frontomedial electrodes, with a group effect $(\mathrm{F}=5.352 ; \quad \mathrm{p}=0.038)$ being found. Comparisons of the differences between the groups show that the schizophrenics presented less voltage in the condition self $(\mathrm{t}=2.386 ; \mathrm{p}=0.033)$ in the frontomedial electrodes, whereas for the condition other, this difference was not statistically significant $(\mathrm{t}=1.971 ; \mathrm{p}=0.07)$ although it did go in the direction expected (Fig. 1).

Similarly, a repeated measures ANOVA with a between-subject factor ( $\mathrm{SCH}$ and normal) and a within-subject (self and other) were performed on the adaptive means for the $75-175 \mathrm{~ms}$ time window on the parietooccipital electrodes, with no significant effects being found. In an exploratory analysis, a difference was observed in the direction expected for electrodes P3 and P4, but it was not statistically significant $(\mathrm{T}=1.833, \mathrm{p}=0.9)$ (Fig. 2).

\section{DISCUSSION}

The results confirm in part the initial hypothesis. When the cortical activity related to self-reference in normal subjects is compared to that of schizophrenic patients, the latter present a distinct electrophysiological pattern in the frontomedial areas of the scalp, however in a temporal window not consistent with the hypothesis. Specifically, in experimental conditions for self-reference, schizophrenics show significantly less amplitude than normal participants, in the frontomedial electrodes in the 180-230 ms time window (211 $\mathrm{ms}$ point of maximum average difference).
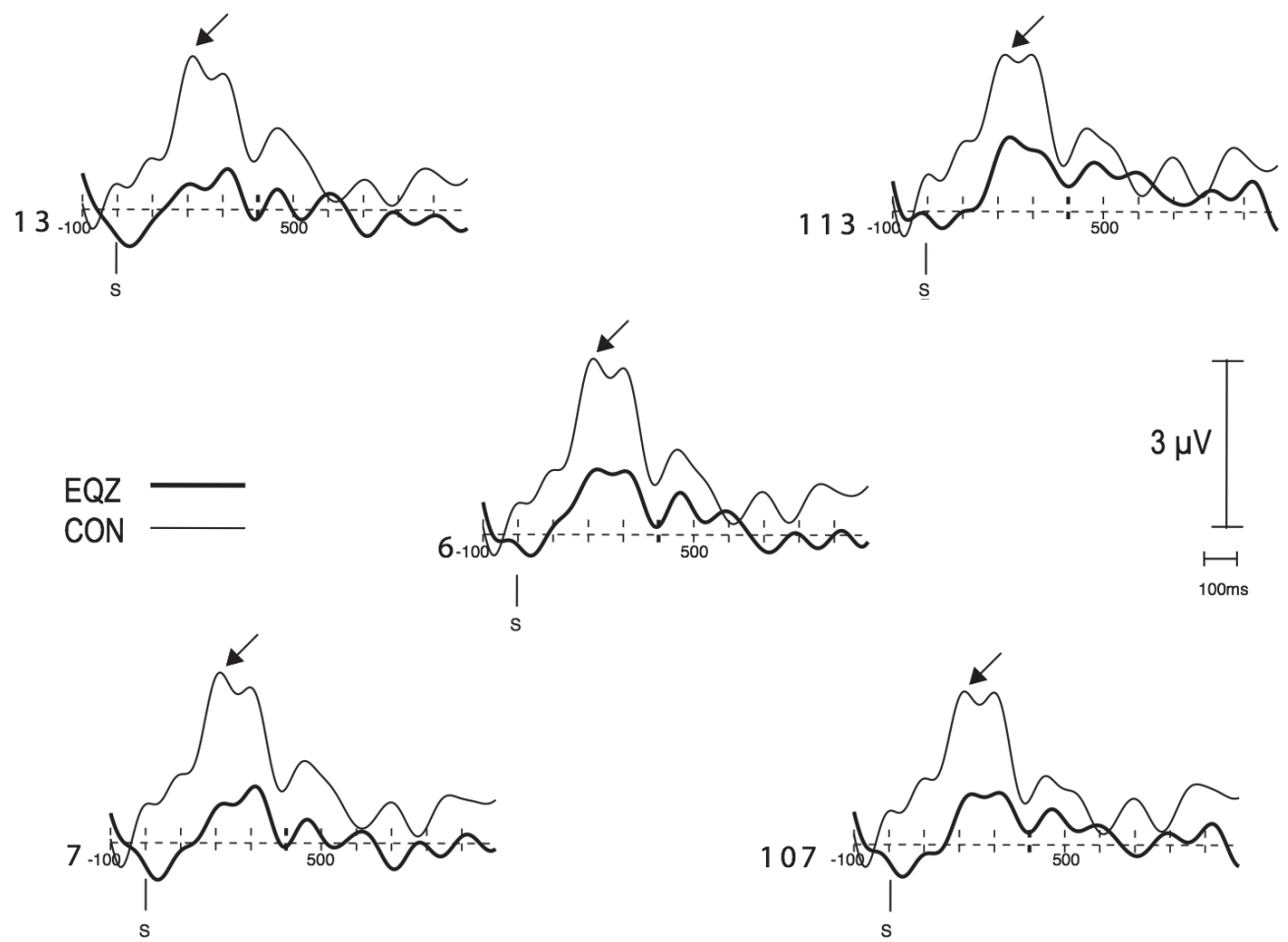

Figure 1: Grand averages in the condition "Oneself" for the frontomedial electrodes. The arrow indicates the point of maximum difference between the groups $(211 \mathrm{~ms}) . \mathrm{SCH}=$ Experiment Group; $\mathrm{CON}=$ Control Group; $\mathrm{S}=$ Stimulus/Zero Time; $\mu \mathrm{V}=$ microvolts . 


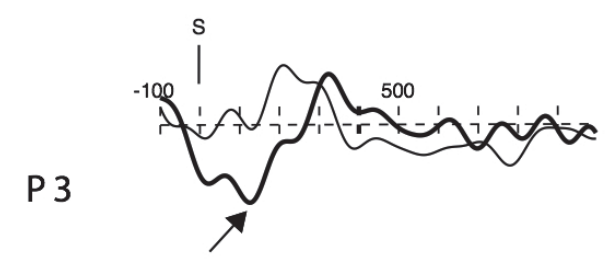

P 4
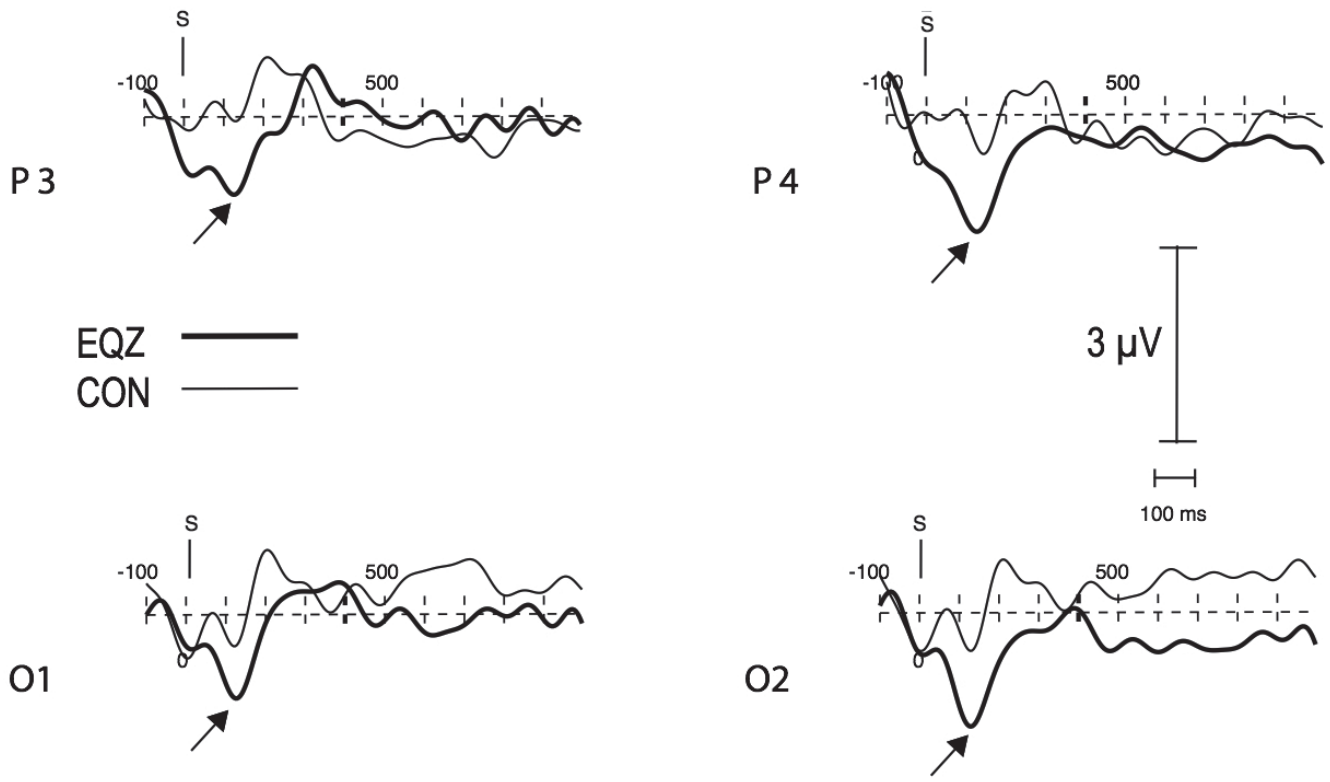

Figure 2: Grand averages in the condition "Oneself" for the parieto-occipital electrodes. The arrow indicates the point of maximum difference between the groups (125 ms). SCH = Experiment Group; $\mathrm{CON}=$ Control Group; $\mathrm{S}=$ Stimulus/Zero Time; $\mu \mathrm{V}=$ microvolts.

This relation is also outlined in the condition of trait attribution of another person, in which schizophrenic subjects present less amplitude in the frontomedial electrodes in the same time window, although there is no statistical significance. In the same way, the topopgraphy of voltage variations in the condition self and other present greater posterior activity (parieto-occipital electrodes) in $\mathrm{SCH}$, although this difference is also not statistically significant.

Altogether, the results allow us to pose some reflections and speculations

First, several studies have shown that frontomedial activity induced during selfreferential tasks typically emerge in late potentials (i.e. posterior to $400 \mathrm{~ms}$ ). In the present study, although frontomedial differences between the groups were observed, these differences emerge in a early temporal window. For this reason, the results are not proof of the hypothesis and must be interpreted with caution

Given that frontolimbic brain structures have been recently related to personal identity (Noerthoff et al., 2006; Kircher et al., 2000; Northoff \& Bremphol, 2004; Tucker et al., 2003; Kjaer et al., 2002) and more generically to the regulation of motivated action (Luu \& Tucker, 2004) as well as to the evaluation of significant events (Luu et al., 200), it is possible to suggest that the early modulation of the word-related meaning creation in a selfreferential context could be affected in $\mathrm{SCH}$. On the other hand, considering that P200 is often considered a pre-lexic component (Brown et al., 1999), in the context of this investigation it could indicate instead a problem in the early visual processing of verbal stimuli. It must be pointed out that studies along these lines have not found any differences in $\mathrm{SCH}$ in this component (Niznikiewicz et al., 1997), suggesting that the experimental condition of self-reference may still be playing a significant role in the modulation of P200. This dilemma is an interesting aspect for future research.

There are additional limitations of the study. In the first place, the small sample of subjects, although similar to other international studies on the 
psychophysiology of $\mathrm{SCH}$, prevents generalizations on the conclusions reached. Similarly, as only one type of $\mathrm{SCH}$ was included, the findings cannot be extrapolated to other forms of the disease. Although the topography of the voltage variations observed in the experimental tasks of interest is in agreement with frontomedial cortical activity, this does not guarantee such a relation. This is why part of our future objectives is the implementation of appropriate analyses (i.e., source analysis) for establishing such an affirmation with greater certainty (study in process). Finally, even when the experimental conditions were controlled and the results congruous with current scientific evidence, the possibility cannot be excluded that the differences found in the study were due to a generic change in the visual perception system, as has been demonstrated in other lines of investigation (Potts et al., 2002).

\section{ACKNOWLEDGEMENTS}

This research was financing by Universidad de La Frontera, Proyecto DIUFRO $\mathrm{N}^{\circ}$ 110607.

\section{REFERENCES}

BLAKEMORE SJ, SMITH J, STEEL R, JOHNSTONE CE, FRITH CD (2000) The perception of self-produced sensory stimuli in patients with auditory hallucinations and passivity experiences: evidence for a breakdown in self-monitoring. Psychol Medicine 30: 1131-1139

BOCKER H, KLEISER M, LEHMAN D, et al. (2006) Executive dysfunction, self, and ego pathology in schizophrenia: an exploratory study of neuropsychology and personality. Compr Psychiatry 47: 7-19

BROWN CM, HAGOORT P, KEURS M (1999) Electrophysiological signatures of visual lexical processing: open- and closed-class words. J. Cognit. Neurosci 11: 261-281

CRAIK F, MOROZ T, MOSCOVITCH M, STUSS D, WINOCUR G, TULVING E, et al. (1999) In search of the self. A PET investigation of self-referential information. Psychol Sci 10: 26-34

CORCORAN R, MERCER G, FRITH CD (1995) Schizophrenia, symptomatology and social inference: investigating "theory of mind" in people with schizophrenia. Schizophr Research 17: 5-13

DAPRATI E, FRANCK N, GEORGIEFF N, PROUST J, PACHERIE E, DALERY J, JEANNEROD M (1997) Looking for the agent: an investigation into consciousness of action and self-consciousness in schizophrenic patients. Cognition 65: 71-86

DSM IV. (1995) Manual diagnóstico y estadístico de los trastornos mentales. Barcelona: Editorial Masson

FARRER C, FRANK N, GEORGIEFF N, FRITH C, DECETY J, JEANNEROD M (2003) Modulating the experience of agency: a positron emission tomography study. Neuroimage 18: 324-333

FORD JM (1999). Schizophrenia: The broken P300 and beyond. Psychophysiology 36: 667-682

FRISTON KJ, ASHBURNER J, FRITH CD, POLINE JB, HEATHER JD, LIDDLE PF (1987) Schizophrenic syndromes, cognitive performance and neurological dysfunction. Psychol Med 17: 49-57

FRITH C, CORCORAN R (1996) Exploring "theory of mind" in people with schizophrenia. Psychol Med 26: 521-530

GALLUP JR. G (1982) Self-awareness and the emergence of theory of mind in primates. Am J Primatol 2: 237248

GALLUP JR. G (1988) Towards a taxonomy of mind in primates. Behav Brain Sci 11: 255-256

GALLUP G, ANDERSON J, PLATEK S (2002) Selfawareness, social intelligence, and schizophrenia. En: Kircher T, David A (eds) The self and schizophrenia: a Neuropsychological Perspective. Cambridge Press. pp: $147-165$

GALLUP JR G, PLATEK S (2002) Cognitive empathy, presupposes self awareness: evidence from phylogeny, ontogeny, neuropsychology, and mental illness. Behav Brain Sci 25(1): 36-37

GOLDBERG TE, GOLD JM (2000) Neurocognitive functioning in patients with schizophrenia. En: Bloom FE, Kupfer DJ (eds) Neuropsychopharmacology: the fourth generation of progress. New York: Raven. pp: 658-671

JEON Y, POLICH J (2001) P300 asymmetry in schizophrenia- A meta-analysis. Psychiatry Res 114: 61-74

JEON Y, POLICH J (2003) Meta-analysis of P300 and schizophrenia- Patients, paradigms, and practical implications. Psychophysiology 40: 684-701

JUNGHOEFER M, ELBERT T, TUCKER D, BRAUN C (1999) The polar effect of the average reference: A bias in estimating the head surface integral in EEG recording. Suppl Clin Neurophysiol 110: 1149-1155

KEENAN J, NELSON A, OCONNOR M, PASCUALLEONE A (2001) Self-recognition and the right hemisphere. Nature 409: 305

KIRCHER T, SENIOR C, PHILLIPS ML, BENSON PJ, BULLMORE E, BRAMMER M, et al. (2000) Toward a functional neuroanatomy of self-processing: effects of faces and words. Brain Res Cogn Brain Res 10: 133144

KIRCHER T, DAVID A (2003) En: Kircher T, David A (eds) The self in neuroscience and psychiatry. Cambridge: Cambridge Press. pp: 445-473.

KJAER TW, NOWAK M, LOU HC (2002) Reflective selfawareness and conscious states: PET evidence for a common midline parietofrontal core, Neuroimage 17: 1080-1086

LUU P, COLLINS P, TUCKER DM (2000). Mood, personality, and self-monitoring: negative affect and emotionality in relation to frontal lobe mechanisms of error monitoring. J Exp Psychol Gen; 129: 43-60

LUU P, TUCKER DM (2004) Self-regulation by the medial frontal cortex: Limbic representation of motive setpoints. En: Beauregard $M$ (ed) Consciousness, emotional self-regulation and the brain. Amsterdam: John Benjamin. pp: 123-161 
MACRAE C, MORAN J, HEATHERTON T, BANFIELD J, KELLEY W (2004) Medial prefrontal activity predicts memory for self. Cereb. Cortex;14: 647-654

NIZNIKIEWICZ MA, ODONNELL BF, NESTOR PG, SMITH L, LAW S, KARAPELOU M, SHENTON ME, MCCARLEY RW (1997) ERP Assessment of Visual and Auditory Language Processing in Schizophrenia. J Abnorm Psychol 106: 85-94

NORTHOFF G, BERMPHOL F (2004) Cortical midline structures and the self. Trends Cogn Sci 8: 102-107

NORTHOFF $G$, HEINZEL A, DE GREEK $M$, BERMPHOL F, DOBROWOLNY, PANKSEEP J (2006) Self-referential processing in our brain-A metaanalysis of imaging studies on the self. Neuroimage 31 : 440-457

ORBACH J, TRAUB AC, OLSON R (1966) Psychological studies of body-image: II. Normative data on the adjustable body-distorting mirror. Arch Gen Psychiatry 14: 41-47

ORELLANA G, SLACHEVSKY A, SILVA, J (2006) Modelos neurocognitivos en la esquizofrenia: rol del córtex prefrontal. Rev Chil Neuro-Psiquiatr 44: 39-47

POLICH J, KOK, A (1995) Cognitive and biological determinants of $\mathrm{P} 300-$ An integrative review. Biol Psychol 41: 113-146

POTTS GF, ODONNELL BF, HIRAYASU Y, MCCARLEY RW (2002) Disruption of neural systems of visual attention in schizophrenia. Arch. Gen. Psychiatry 59: 418-424

ROBRICHT F, PRIEBE S (2004) Ego-pathology and common symptom factors in schizophrenia. J Nerv Ment Dis 192: 446-449

SAAS L (2003) Self-disturbance in schizophrenia: hiperreflexivity and diminished self-affection. En: Kircher T, David A (eds) The Self in Neuroscience and Psychiatry, Cambridge: Cambridge Press. pp: 242-271

SAAS LA, PARNAS J (2003) Schizophrenia, consciousness, and the self. Schizophr Bull 29: 427444

SCHARFETTER C (1981) Ego-psychopathology: The concept and its empirical evaluation. Psychol Med 11: 273-280

SCHARFETTER C (1995) The ego/self experience of schizophrenics. Arch Neurol Psychiatr 146: 200-206

SIGMUNDSSON T, SUCKLING J, MAIER M, WILLIAMS SCR, BULLMORE ET, GREENWOOD K (2001) Structural abnormalities in frontal, temporal and limbic regions and interconnecting white matter tracts in schizophrenia. Am J Psych 158: 234-243

TORRES M, SILVA J, SILVA L (2007) Evaluación de rasgos personales, self, esquizofrenia y estructuras de la línea media cortical. Rev Méd Chile 135: 641-648

TRAUB A, ORBACH J (1964) Psychophysical studies of body image: I. The adjustable body-distorting mirror. Arch Gen Psychiatry 11: 53-66

TUCKER DM, LUU P, DESMOND R, HARTRYSPEISER, DAVEY C, FLAISCH T (2003) Corticolimbic mechanisms in emotional decisions. Emotion 3: 127-149

VOGELEY K, BUSSFELD P, NEWEN A, HERRMANN S, HAPPE S, FALKAI P, ET AL (2001) Mind reading: Neural Mechanisms of theory of mind and self perspective. Neuroimage 14: 170-181

WOODRUFF PW, WRIGHT IC, SHURIQUIE N, RUSSOUW H, RUSHE T, HOWARD RJ (1997) Structural brain abnormalities in male schizophrenics reflect fronto-temporal dissociation. Psychol Med 27: $1257-1266$

YOUNG CE, ARIMA K, XIE J, HU L, BEACH TG, FALKAI P (1998) SNAP-25 deficit and hippocampal connectivity in schizophrenia. Cereb Cortex 8: 261-268

ZYSSET S, HUBER O, FERSTL E, VON CRAMON DY (2002) The anterior frontomedian cortex and evaluative judgment: an fMRI study. Neuroimage 15: 983-991 